\title{
Temperature Controlled of Self-Oscillating for Polymer Chains Induced by BZ Reaction with $\mathrm{Fe}(\text { phen })_{3}$ Catalyst
}

\author{
Jie Ren ${ }^{1,2}$, Mengqi $\mathrm{Yao}^{2}$, Guangcheng Zhang ${ }^{1}$, Jinfen $\mathrm{Gu}^{2}$, $\mathrm{Li} \mathrm{Tao}^{2} \& \mathrm{Wu} \mathrm{Yang}^{2}$ \\ ${ }^{1}$ School of Natural and Applied Science, Northwestern Polytechnical University, Xi'an 710072, PR China \\ ${ }^{2}$ Chemistry \& Chemical Engineering College, Northwest Normal University, Key Lab of Bioelectrochemtry \& \\ Environmental Analysis of Gansu, Lanzhou 730070, PR China \\ Correspondence: Jie Ren, School of Natural and Applied Science, Northwestern Polytechnical University, Xi'an \\ 710072, PR China. E-mail: jieren@nwnu.edu.cn
}

Received: April 27, 2015 Accepted: June 7, 2015 Online Published: June 17, 2015

doi:10.5539/jmsr.v4n3p98

URL: http://dx.doi.org/10.5539/jmsr.v4n3p98

\begin{abstract}
The polymer chain with $\mathrm{Fe}(\mathrm{phen})_{3}$-catalyzed was demonstrated to occur self-oscillation phenomenon in BZ reaction system. The self-oscillation polymer composed of $\mathrm{N}$-isopropylacrylamide and $\mathrm{Fe}(\mathrm{phen})_{3}$ catalyst moiety, which were synthesized by radical polymerization. It was found that the self-oscillation parameters (induction period, $\mathrm{T}_{\mathrm{i}}$, oscillation period, $\mathrm{T}_{\mathrm{p}}$ and amplitude) could be regulated by subtle changes of temperature. It can be well explained by the FKN mechanism.
\end{abstract}

Keywords: self-oscillation, poly(NIPAAm- $\left.\mathrm{co}-\mathrm{Fe}(\mathrm{phen})_{3}\right)$, temperature control

\section{Introduction}

Conventional stimuli-responsive hydrogels, which change their properties in response to external stimulus, such as temperature, $\mathrm{pH}$, electric field and magnetic field, have been studied extensively for applications in drug delivery systems, biosensors, and actuators, etc (Tanaka et al., 1980; Annaka \& Tanaka, 1992; Chen \& Hoffman, 1995; Hirokawa \& Tanaka, 1984; Bae, Okano, \& Kim, 1990; Yoshida et al., 1995). Yoshida's group reported a novel polymeric gel which autonomously swelled and de-swelled periodically in a closed homogeneous solution without any external stimuli, similar to autonomic phenomena in life such as heartbeat, brain waves, periodic hormone secretion, etc. The mechanical oscillation is achieved by coupling nonlinear chemical dynamics with polymers, transferring the dissipating chemical energy of a self-oscillating reaction to the driving force for the conformation changing of the polymers. The coupling of oscillating reactions with polymerization processes may provide methods for construction of novel materials capable of transmitting chemical energy. One area of research has been the construction of pulsating gels for periodic delivery of drugs, with oscillating chemical reactions supplying the necessary energy.

In general, the Belousov-Zhabotinsky (BZ) reaction (Noszticzius \& Bódiss, 1979; Field, Körös, \& Noyes, 1972) was employed for the simple model for a spatiotemporal structure in an unstirred solution and with periodicity in a stirred solution. Yoshida's group prepared a series of copolymer gels in which ruthenium(II) tris-(2,2'-bipyridine) $\left(\mathrm{Ru}(\mathrm{bpy})_{3}{ }^{2+}\right)$, a catalyst for the BZ reaction, was covalently bonded to the polymer chains (Yoshida, Takahashi, Yamaguchi, \& Ichijo, 1996; Yoshihiro, Masayuki, \& Yoshida, 2003; Suzuki, Taniguchi, \& Yoshida, 2009; Hidaka \& Yoshida, 2011; Yoshida, Sakai, Ito, \& Yamaguchi, 2002; Hara et al., 2005; Suzuki \& Yoshida, 2008). There the catalyst acts as a transducer to convert its periodical redox changes into the mechanical oscillation of the polymer network through the hydrophilicity changes of the polymer chain.

Up to now, the polymer system has been studied for application to self-walking gel robot, actuator and mass transport system, etc (Murase, Maeda, Hashimoto, \& Yoshida, 2009; Mitsumata, Ikeda, Gong, \& Osada, 2000; Tateyama, Shibuta, \& Yoshida, 2008; Maeda, Hara, \& Yoshida, 2008). Besides, the self-oscillating macrogels would have potential applications such as pumps with autonomous beating, oscillatory drug release synchronized with cell cycles, etc (Weissman, Sunkara, Tse, \& Asher, 1996; Suzuki, McGrath, Kawaguchi, \& Lyon, 2007; Lyon et al., 2004). Moreover, self-oscillating microgel particles (less than $1 \mu \mathrm{m}$ in diameter) have been synthesized by surfactant free aqueous precipitation polymerization (Suzuki, Sakai, \& Yoshida, 2008; Suzuki \& Yoshida, 2008). Due to the properties of colloidal dispersions (Pelton, 2000; Nayak \& Lyon, 2005; Saunders \& 
Vincent, 1999; Kawaguchi, 2000), microgel particles are used as microreactors, emulsifiers, and photonic crystals (Suzuki, McGrath, Kawaguchi, \& Lyon, 2007; Suzuki \& Kawaguchi, 2006; Suzuki, Tsuji, \& Kawaguchi, 2007). Therefore, the self-oscillating microgels may be useful not only as artificial oscillators, but also as rheological modifiers, and so on.

However, this kind of self-oscillating polymer system is too expensive for application in many fields owing to the use of expensive rare metal $\mathrm{Ru}$ as the catalyst moiety required for BZ reaction. Recently, Hara developed a novel self-oscillating polymer by covalently bonding the $\mathrm{Fe}(\mathrm{bpy})_{3}$ moiety to the polymer chain, which acted as the metal catalyst for the BZ reaction. However, the amplitude of the soluble-insoluble self-oscillation of poly(NIPAAm-co-Fe(bpy) $)_{3}$ ) was significantly smaller than that of the corresponding Ru-based self-oscillating polymer system.

To achieve the applications of self-oscillating polymers, we developed a novel self-oscillating polymer by covalently bonding a $\mathrm{Fe}(\mathrm{phen})_{3}$ moiety, which acted as the metal catalyst for the $\mathrm{BZ}$ reaction. It was demonstrated that the polymer underwent soluble-insoluble self-oscillation that originated from the periodic change in the solubility of the $\mathrm{Fe}($ phen) 3 catalyst moiety (Ren et al., 2015). In order to clarify the effect of temperature on the polymer chains oscillation, and to understand how self-oscillation of polymer can be controlled, the influence of temperature on the self-oscillation of the polymer chain was investigated in the present study.

\section{Experimental}

\subsection{Materials}

$\mathrm{N}$-isopropylacrylamide (NIPAAm), azo-bis-isobutyronitrile (AIBN) were brought from Shanghai Zhongqin chemical industry and used without further purification. Ethanol, dichloromethane and methanol (Tianjin Guangfu fine chemical industry research institute, Tianjin, China), and $\mathrm{FeSO}_{4} \cdot 7 \mathrm{H}_{2} \mathrm{O}$, malonic acid (MA), $\mathrm{KBrO}_{3}$, $\mathrm{H}_{2} \mathrm{SO}_{4}, \mathrm{Ce}_{2}\left(\mathrm{SO}_{4}\right)_{3}$ and $\mathrm{Ce}\left(\mathrm{SO}_{4}\right)_{2}$ were analytical regents and used as received. 5-acrylamide-phenanthroline (5-AM-phen) was synthesized by the method in references. The deionized water was used throughout the experiments.

\subsection{Preparation of Poly(NIPAAm-co-Fe(phen $)_{3}$ )}

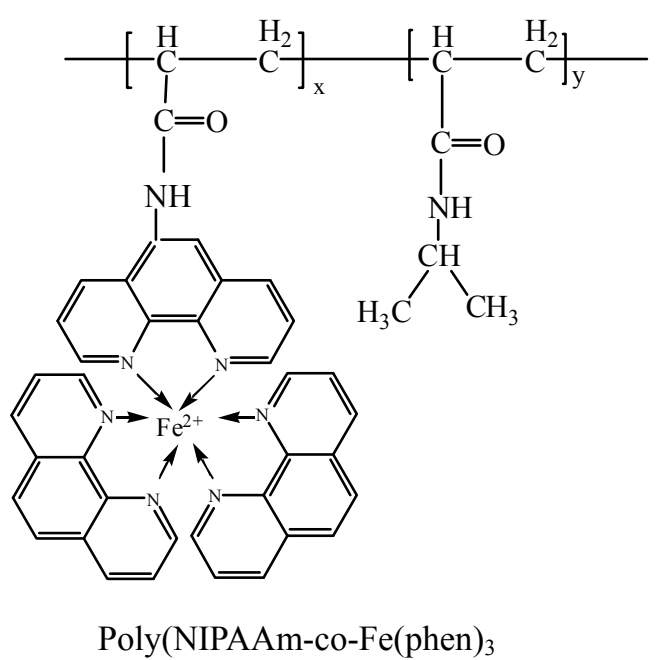

Figure 1. The chemical structure of the self-oscillating polymer chain

The self-oscillating polymer chain with the Fe catalyst moiety(as shown Figure. 1) was synthesized via free-radical polymerization as previously reported (Ren et al., 2015). The process is as following: N-isopropylacrylamide (NIPAAm, $5.0 \mathrm{~g}$ ), 5-acrylamide-phenanthroline (5-AM-phen, $0.20 \mathrm{~g}$ ), and azo-bis-isobutyronitrile (AIBN, $0.05 \mathrm{~g}$ ) were dissolved in ethanol $(25 \mathrm{~g})$. The mixture was poured into a three-neck flask equipped with a stirrer, a condenser, and a nitrogen gas inlet. The polymerization reaction was carried at $80{ }^{\circ} \mathrm{C}$ for $6 \mathrm{~h}$ with $\mathrm{N}_{2}$ bubbling. The obtained polymer was dissolved in dichloromethane. The solution of $\mathrm{FeSO}_{4}$ in methanol was added dropwise into the polymer solution with stirring. Finally, the solution of phenanthroline in ethanol was added with stirring at room temperature. The resulting sample was dialyzed with ethanol for a week while changing ethanol frequently, and then dialyzed with water for a week, freeze-dried finally. 


\subsection{Measurement of Redox Potential Self-Oscillation}

The experiments were performed in a glass reactor $(c a .50 \mathrm{~mL})$ coupled with a SY-601 thermostat and a Model ML-902 magnetic stirrer. A mixture containing malonic acid, $\mathrm{KBO}_{3}, \mathrm{H}_{2} \mathrm{SO}_{4}$ and poly(NIPAAm-co-Fe(phen) $)_{3}$ ) was placed in the reactor. A CHI-832 electrochemistry analyzer (Shanghai Chenhua Instrument Company, China) was directly connected to the reactor through two Pt-electrodes (Rex, 213, China) as the working electrode and the auxiliary electrode and a $\mathrm{Hg}_{2} \mathrm{SO}_{4}$ reference electrode to record the potential changes.

\subsection{Measurement of Transmittance Self-Oscillation}

The solution was mixed as the measurement of redox potential self-oscillation and stirred until its color began to change between red and light blue, then the transmittance self-oscillation was measured. A wavelength of $389 \mathrm{~nm}$ was also used because of being the isosbestic point of the reduced and oxidized states of the polymer chain. The time course of the transmittance at $389 \mathrm{~nm}$ was monitored using an UV-Vis spectrophotometer.

\section{Results and Discussion}

A wide variety of metal ions and metal complex catalysts have been used in the $\mathrm{BZ}$ reaction: $\mathrm{Ce}^{3+}, \mathrm{Mn}^{2+}$, $\left[\mathrm{Fe}(\text { phen })_{3}\right]^{2+},\left[\mathrm{Fe}(\mathrm{bpy})_{3}\right]^{2+},\left[\mathrm{Ru}(\mathrm{bpy})_{3}\right]^{2+}$, and so on. These catalysts fill the requirement that they are capable of a single electron transfer and have two stable oxidation states separated by a potential of 1.0-1.5 V/SCE. Despite having some features in common, these catalysts can sometimes have remarkably different effects on the observed behavior of the $\mathrm{BZ}$ reaction. There is a pronounced color change from red to blue as ferroin $\left(\mathrm{Fe}(\mathrm{phen}){ }_{3}{ }^{2+}\right)$ is oxidized to ferriin $\left(\mathrm{Fe}(\mathrm{phen}){ }_{3}{ }^{3+}\right)$. Smoes emphasized the fact that ferroin does not react in the same manner as cerium in the BZ reaction (Smoes, 1979). In fact, the ferriin/ferroin couple has a lower standard reduction potential $(1.06 \mathrm{~V})$ than that of $\mathrm{Ce}^{4+} / \mathrm{Ce}^{3+}(1.44 \mathrm{~V})$. Keki, Magyar, Beck and Gaspar (1992) demonstrate that direct oxidation of ferroin by bromine species other than $\mathrm{BrO}_{2} \bullet$ radical species is possible due to the low redox potential of the catalyst couple. Therefore, the behavior of the ferroin-catalysed BZ can be explained by the following reactions.

$$
\begin{gathered}
2 \mathrm{Fe}(\text { phen })_{3}{ }^{2+}+\mathrm{BrO}_{3}{ }^{-}+3 \mathrm{H}^{+} \rightarrow 2 \mathrm{Fe}(\text { phen })_{3}{ }^{3+}+\mathrm{HBrO}_{2}+\mathrm{H}_{2} \mathrm{O} \\
2 \mathrm{Fe}(\text { phen })_{3}{ }^{2+}+\mathrm{HBrO}_{2}+2 \mathrm{H}^{+} \rightarrow 2 \mathrm{Fe}(\text { phen })_{3}{ }^{3+}+\mathrm{HOBr}+\mathrm{H}_{2} \mathrm{O} \\
2 \mathrm{Fe}(\text { phen })_{3}{ }^{2+}+\mathrm{HOBr}+\mathrm{H}^{+} \rightarrow 2 \mathrm{Fe}(\text { phen })_{3}{ }^{3+}+\mathrm{Br}^{-}+\mathrm{H}_{2} \mathrm{O} \\
2 \mathrm{Fe}(\text { phen })_{3}{ }^{2+}+\mathrm{Br}_{2} \rightarrow 2 \mathrm{Fe}(\text { phen })_{3}{ }^{3+}+2 \mathrm{Br}
\end{gathered}
$$

Körös performed calorimetric studies on the $\mathrm{BZ}$ reaction and determined that the heat released per mole bromated consumed $(650 \mathrm{~kJ})$ in the same and is independent of the catalyst used. Most of heat released during FKN process $\mathrm{C}$, i.e. the oxidation of MA or BrMA by $\mathrm{Ce}^{4+}$. Although the rate of heat production is oscillatory, however, the temperature of the system does not oscillate in the BZ system. Therefore, the effect of temperature on the self-oscillation is completely from the surrounding temperature changing, rather than the BZ system itself.

The self-oscillating mechanism of the polymer is due to the change in the hydrophilic-hydrophobic properties of polymer chains with oxidation and reduction. With the development of BZ reaction, $\mathrm{Fe}(\mathrm{phen})_{3}$ moiety hanging on the polymer chain is oxidized or reduced. When $\mathrm{Fe}(\mathrm{III})$ is reduced to $\mathrm{Fe}(\mathrm{II})$, the polymer chains stretch and the solubility of the polymer increases due to the good hydrophilicity and solubility of $\mathrm{Fe}(\mathrm{phen})_{3}{ }^{2+}$. However, when $\mathrm{Fe}(\mathrm{II})$ is oxidized to $\mathrm{Fe}(\mathrm{III})$ in BZ medium, the polymer chains curl and twist each other and the solubility of $\mathrm{Fe}(\mathrm{phen}){ }_{3}{ }^{3+}$ decreases correspondingly. Therefore, the polymer undergoes soluble-insoluble self-oscillation along with the periodic change of $\mathrm{Fe}(\mathrm{phen})_{3}$ catalyst moiety between the oxidation and reduction states in $\mathrm{BZ}$ reaction. The temperature plays an important part in the dynamics of the BZ system. Figure 2 shows the redox potential self-oscillation of the poly(NIPAAm-co-Fe(phen) $)_{3}$ ) solution at different temperature against fixed concentrations of the BZ system and Figure 3 shows the oscillation profiles of optical transmittance (T\%) with the same solution. Note that, when the temperature is lower than $19^{\circ} \mathrm{C}$, both the periodic redox potential and transmittance changes could no longer be observed due to the reaction rate being too slow. However, when the temperature is higher than $29^{\circ} \mathrm{C}$, there is some flocculent substance in the system which adheres onto the electrodes due to the temperature sensitivity of $\mathrm{N}$-isopropylacrylamide. Therefore, the self-oscillation parameters were compared when the temperature was in the range of $22-28^{\circ} \mathrm{C}$. 


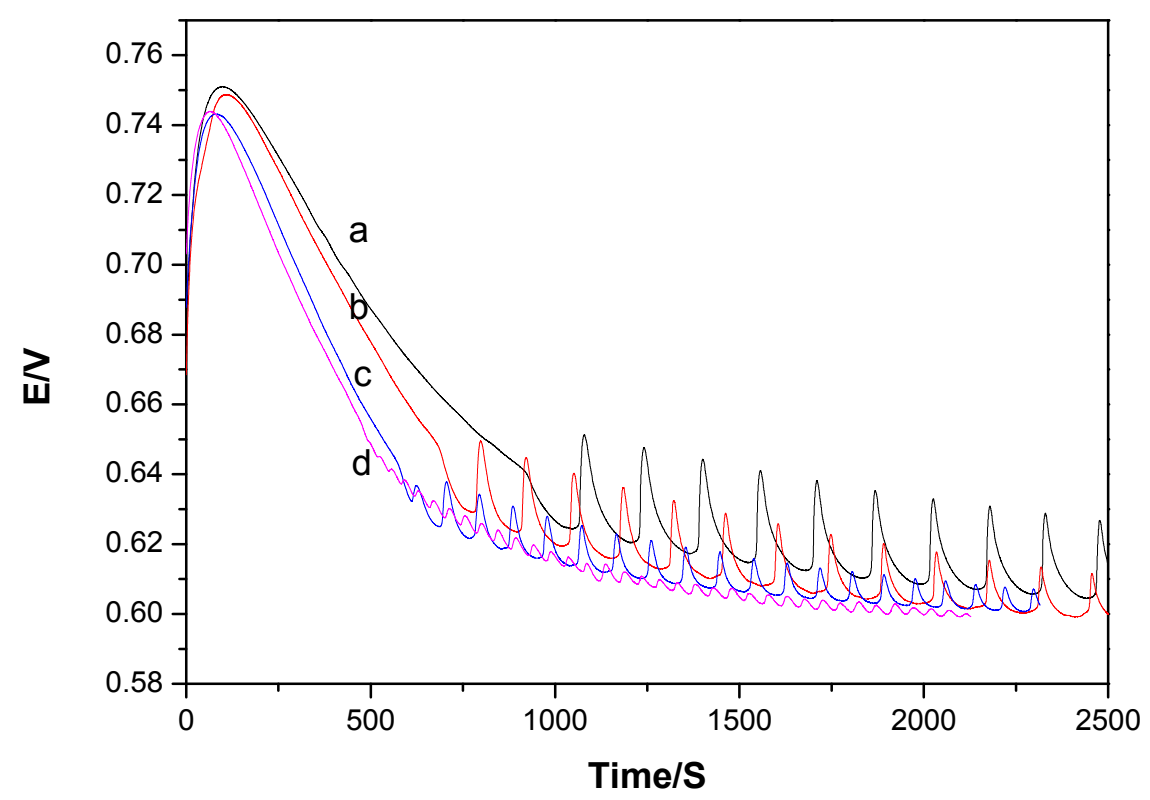

Figure 2. Typical oscillation waveforms of redox potential with different temperature. a: $22^{\circ} \mathrm{C}$, b: $24^{\circ} \mathrm{C}, \mathrm{c}: 26^{\circ} \mathrm{C}$, d: $28^{\circ} \mathrm{C}$. The common conditions: $[\text { polymer }]_{0}=0.20 \%,\left[\mathrm{KBrO}_{3}\right]_{0}=0.0625 \mathrm{~mol} / \mathrm{L},[\mathrm{MA}]_{0}=0.135 \mathrm{~mol} / \mathrm{L}$, $\left[\mathrm{H}_{2} \mathrm{SO}_{4}\right]_{0}=0.175 \mathrm{~mol} / \mathrm{L}$

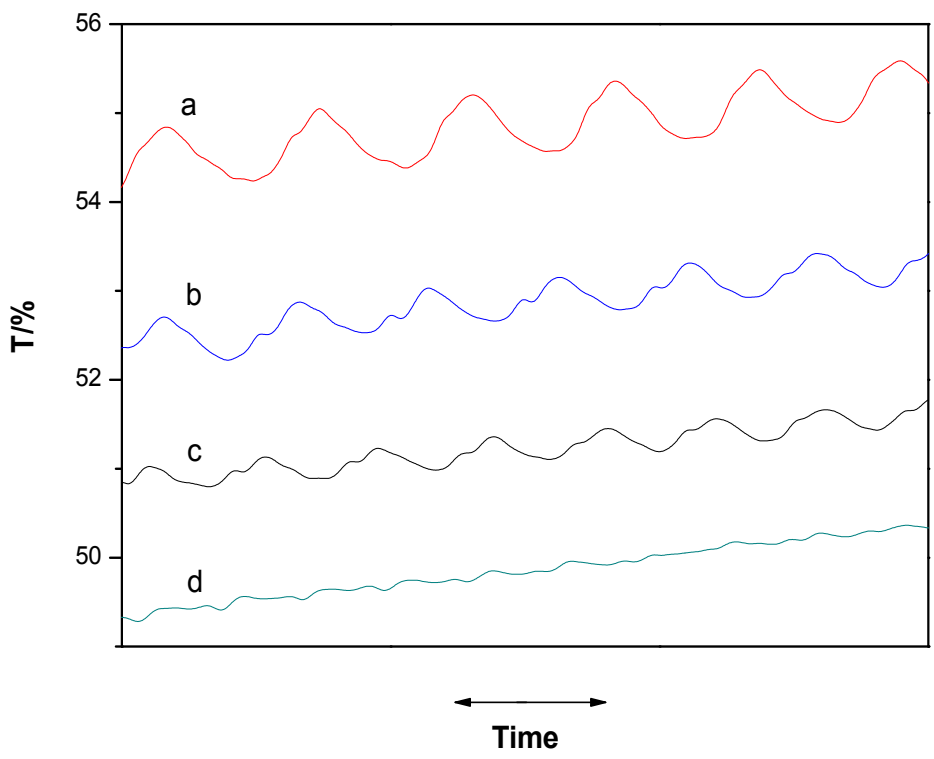

Figure 3. Typical oscillation waveforms of transmittance with different temperature. The experimental conditions are the same as which in Figure 2

In the induction period, BrMA is accumulating. A crucial amount of BrMA is necessary to induce regular oscillations. The rate for production of BrMA increases with increasing temperature, and the induction period decreases correspondingly as shown in Figure 4(a). We also compared the oscillation periods with different temperature. In this study, the average value of the periods between the second and the sixth oscillation were regarded as the oscillation period. The frequency of oscillation is mainly determined by the rate of removal of bromide. In the FKN mechanism, bromide ion is consumed by reaction with bromated ion mainly as in R5.

$$
\mathrm{BrO}_{3}{ }^{-}+3 \mathrm{H}^{+}+\mathrm{Br}^{-} \rightarrow 3 \mathrm{Br}_{2}+3 \mathrm{H}_{2} \mathrm{O}
$$

The period of oscillation decreases for all reactions rate involved increasing at high temperature. So as shown in Figure $4(\mathrm{a})$, the oscillation period $\left(\mathrm{T}_{\mathrm{p}}\right)$ decreased with increasing temperature. 
Figure 4(b) shows the dependence of the amplitudes of the oscillation on temperature. It can be seen from the figure, the oscillation amplitudes both of redox potential and transmittance decreased with the increasing of temperature. The main component of the polymer is $\mathrm{N}$-isopropylacrylamide with temperature sensitivity. The lower critical solution temperature of $\mathrm{N}$-isopropylacrylamide is $32^{\circ} \mathrm{C}$. Suzuki and Yoshida (2008) suggested that the dramatic change in oscillation waveform and amplitude is related to the difference in colloidal stability between in the $\mathrm{Ru}(\mathrm{II})$ and the $\mathrm{Ru}(\mathrm{III})$ states for self-oscillation polymer containing $\mathrm{Ru}(\mathrm{bpy})_{3}$ moiety. At low temperature, the polymer chain is stretch and the $\mathrm{Fe}(\mathrm{phen})_{3}$ moiety hanging on the chain catalyzes the BZ reaction effectively and changes between the oxidation and reduction states freely. The $\mathrm{Fe}(\mathrm{phen})_{3}$ moiety can exist only in its oxidation state at a certain time and in its reduction state at another certain time. That is to say, $\mathrm{Fe}(\text { phen })_{3}$ moiety can transfer from one state to the other completely. The concentration difference between the two states is the maximum at oxidation state or reduction state. Therefore, both the redox potential and transmittance amplitudes are big at low temperature. However, at high temperature and close to the lower critical solution temperature of $\mathrm{N}$-isopropylacrylamide, the phase separation is coming, and the polymer chains curls and twists each other. Some of the moiety is embedded and can't contact with BZ medium adequately. Both the reduction of $\mathrm{Fe}(\mathrm{phen})_{3}{ }^{3+}$ and the oxidation of $\mathrm{Fe}(\mathrm{phen})_{3}{ }^{2+}$ are incompletely, the concentration difference between the two states become smaller on raising the temperature and the amplitudes smaller correspondingly.
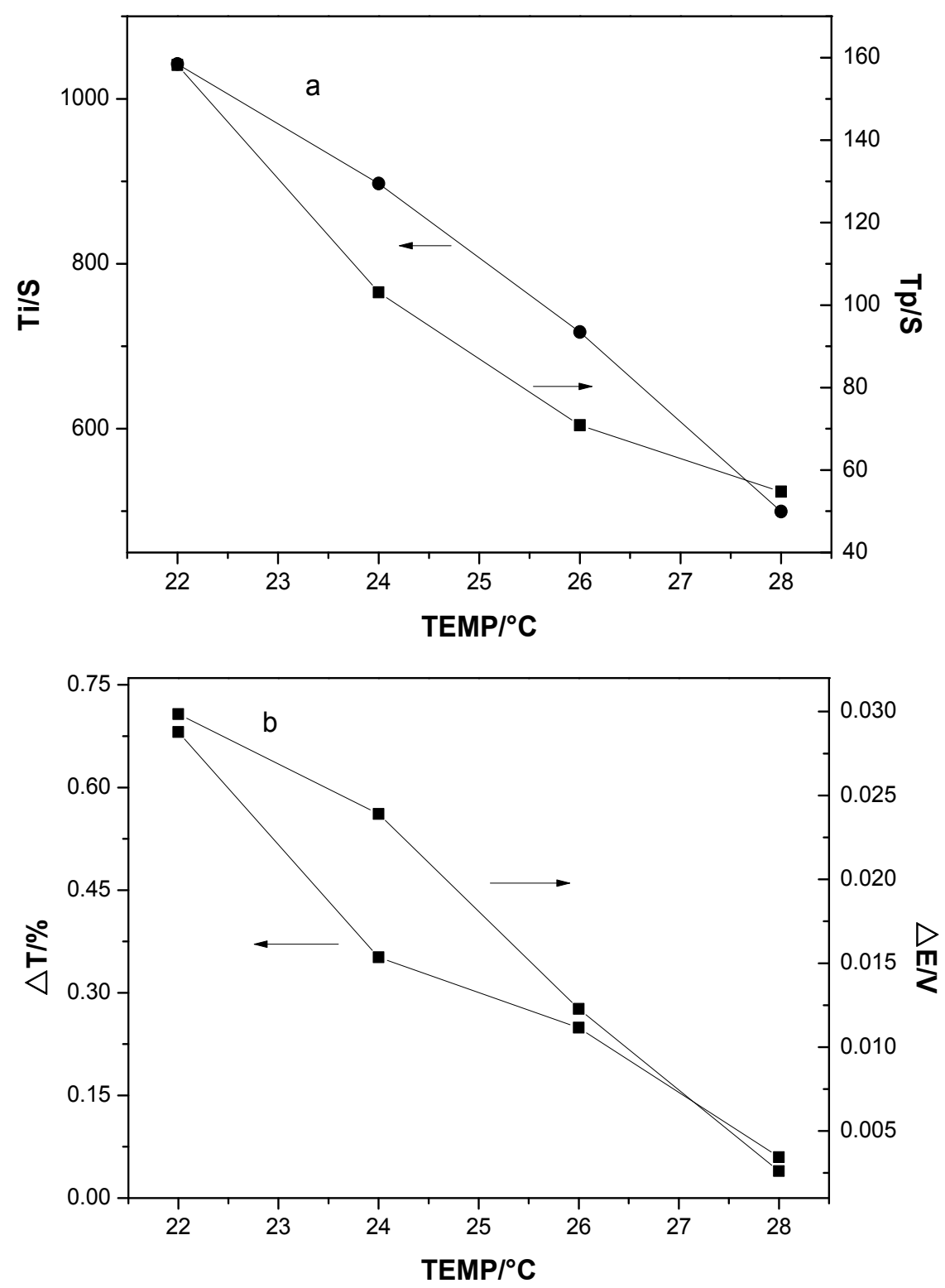

Figure 4. Effect of temperature on induction period and oscillation period (a), amplitude (b) of the self-oscillation 


\section{Conclusions}

The polymer chain containing $\mathrm{Ru}(\mathrm{bpy})_{3}$ catalyst is well-known as a self-oscillation phenomenon. Photo-irradiation and temperature have been employed to switch the self-oscillation on and off. In the present work, for the first time we found that the self-oscillation could be controlled by temperature. When the temperature increased, the oscillation frequency increased and the amplitudes both of redox potential and transmittance decreased correspondingly.

\section{Acknowledgments}

This work was supported in part by the Basic Project of Science and Research of Colleges and Universities of Gansu Province (5001-109), the Project for Young Teacher of Northwest Normal University (NWNU-LKQN-13-6).

\section{Referrences}

Annaka, M., \& Tanaka, T. (1992). Multiple phases of polymer gels. Nature, 355, 430-432. http://dx.doi.org/ $10.1038 / 355430 \mathrm{a} 0$

Bae, Y. H., Okano, T., \& Kim, S. W. (1990). Temperature dependence of swelling of crosslinked poly (N, $\mathrm{N}^{\prime}$-alkyl substituted acrylamides) in water. Journal of Polymer Science Part B, 28, 923-936. http://dx.doi.org/ 10.1002/polb.1990.090280609

Chen, G., \& Hoffman, A. S. (1995). Graft copolymers that exhibit temperature-induced phase transitions over a wide range of $\mathrm{pH}$. Nature, 373, 49-52. http://dx.doi.org/10.1038/373049a0

Field, R. J., Körös, E., \& Noyes, R. M. (1972). Oscillations in chemical systems. II. Thorough analysis of temporal oscillation in the bromate-cerium-malonic acid system. Journal of the American Chemical Society, 94(25), 8649-8664. http://dx.doi.org/ 10.1021/ja00780a001

Hara, Y., Sakai, T., Maeda, S., Hashimoto, S., \& Yoshida, R. (2005) Self-oscillating soluble-insoluble changes of a polymer chain including an oxidizing agent induced by the Belousov-Zhabtinsky reaction. Journal of Physical Chemistry B, 109, 23316-23319. http://dx.doi.org/10.1021/jp055157y

Hidaka, M., \& Yoshida, R. (2011). Self-oscillating gel composed of thermosensitive polymer exhibiting higher LCST. Journal of Controlled Release, 150, 171-176. http://dx.doi.org/ 10.1016/j.jconrel.2010.11.026

Hirokawa, Y., \& Tanaka, T. (1984). Volume phase transition in a nonionic gel. The Journal of Chemical Physics, 81, 6379-6380. http://dx.doi.org/10.1063/1.447548

Kawaguchi, H. (2000). Functional polymer microspheres. Progress in Polymer Science, 25, 1171-1210. http://dx.doi.org/10.1016/S0079-6700(00)00024-1

Keki, S., Magyar, I., Beck, M.T., \& Gaspar, V. (1992). Modeling the oscillatory bromate oxidation of ferroin in open systems. The Journal of Chemical Physics, 96(4), 1725-1729. http://dx.doi.org/ 10.1021/j100183a042

Lyon, L. A., Debord, J. D., Debord, S. B., Jones, C. D., McGrath, J. G., Serpe, \& M. J. (2004). Microgel colloidal crystals. Journal of Physical Chemistry B, 108, 19099-19108. http://dx.doi.org/ 10.1021/jp048486j

Maeda, S, Hara, Y, \& Yoshida, R. (2008). Control of the dynamic motion of a gel actuator driven by the Belousov-Zhabotinsky reaction. Macromolecular Rapid Communications, 29, 401-405. http://dx.doi.org/ 10.1002/marc.200700717

Mitsumata, T., Ikeda, K., Gong, J. P., \& Osada, Y. (2000). Controlled motion of solvent-driven gel motor and its application as a generator. Langmuir, 16, 307-312. http://dx.doi.org/ 10.1021/la990483o

Murase, Y., Maeda, S., Hashimoto, S., \& Yoshida, R. (2009). Design of a mass transport surface utilizing peristaltic motion of a self-oscillating gel. Langmuir, 25, 483-489. http://dx.doi.org/ 10.1021/la8029006

Nayak, S., \& Lyon, L. A. (2005). Soft nanotechnology with soft nanoparticles. Angewandte Chemie, International Edition, 44, 7686-7708. http://dx.doi.org/ 10.1002/anie.200501321

Noszticzius, Z., \& Bódiss, J. (1979). A heterogeneous chemical oscillator. The Belousov-Zhabotinskii-type reaction of oxalic acid. Journal of the American Chemical Society, 101, 3177-3182. http://dx.doi.org/10. 1021/ja00506a007

Pelton, R. (2000). Temperature-sensitive aqueous microgels. Advances in Colloid and Interface Science, 85, 1-33. http://dx.doi.org/ 10.1016/S0001-8686(99)00023-8 
Ren, J., Yao, M. Q., Zhang, G. C., Yang, X. C., Gu, J. F., \& Yang, W. (2015). Self-oscillating soluble-insoluble changes of polymer chain. Journal of Polymer Research, 22(44), 1-6. http://dx.doi.org/10.1007/s10965 $-015-0686-6$.

Saunders, B. R., \& Vincent, B. (1999). Microgel particles as model colloids: theory, properties and applications. Advances in Colloid and Interface Science, 80, 1-25. http://dx.doi.org/10.1016/S0001-8686(98)00071-2

Smoes, M. L. (1979). Period of homogeneous oscillations in the ferroin - catalyzed Zhabotinskii system. The Journal of Chemical Physics, 71(11), 4669-4670. http://dx.doi.org/ 10.1063/1.438250

Suzuki, D., \& Kawaguchi, H. (2006). Hybrid microgels with reversibly changeable multiple brilliant Color. Langmuir, 22(8), 3818-3822. http://dx.doi.org/ 10.1021/la052999f

Suzuki, D., \& Yoshida, R. (2008). Effect of initial substrate concentration of the Belousov-Zhabotinsky reaction on self-oscillation for microgel system. Journal of Physical Chemistry B, 112, 12618-12624. http://dx.doi.org/10.1021/jp8037973

Suzuki, D., \& Yoshida, R. (2008). Temporal control of self-oscillation for microgels by cross-linking network structure. Macromolecules, 41(15), 5830-5838. http://dx.doi.org/ 10.1021/ma800684d

Suzuki, D., McGrath, J. G., Kawaguchi, H., \& Lyon, L. A. (2007). Colloidal crystals of thermosensitive, core/shell hybrid microgels. Journal of Physical Chemistry C, 111, 5667-5672. http://dx.doi.org/ 10.1021/jp068535n

Suzuki, D., Sakai, T., \& Yoshida, R. (2008). Self-flocculating/self-dispersing oscillation of microgels. Angewandte Chemie, International Edition, 47, 917-920. http://dx.doi.org/ 10.1002/ange.200703953

Suzuki, D., Taniguchi, H., \& Yoshida, R. (2009). Autonomously oscillating viscosity in microgel dispersions. Journal of the American Chemical Society, 131(34), 12058-12059. http://dx.doi.org/ 10.1021/ja904677g

Suzuki, D., Tsuji, S., \& Kawaguchi, H. (2007). Janus microgels prepared by surfactant-free pickering emulsion-based modification and their self-assembly. Journal of the American Chemical Society, 129, 8088-8089. http://dx.doi.org/ 10.1021/ja072258w

Tanaka, T., Fillmore, D., Sun, S. T., Nishio, I., Swislow, G., \& Shah, A. (1980). Phase transitions in ionic gels. Physical Review Letters, 45, 1636-1639. http://dx.doi.org/10.1103/PhysRevLett.45.1636

Tateyama, S., Shibuta, Y., \& Yoshida, R. (2008). Direction control of chemical wave propagation in self-oscillating gel array. Journal of Physical Chemistry B, 112, 1777-1782. http://dx.doi.org/10.1021/ jp709882h

Weissman, J. M., Sunkara, H. B., Tse, A. S., \& Asher, S. A. (1996). Thermally switchable periodicities and diffraction from mesoscopically ordered materials. Science, 274, 959-960. http://dx.doi.org/ 10.1126/science.274.5289.959

Yoshida, R., Sakai, T., Ito, S., \& Yamaguchi, T. (2002). Self-oscillation of polymer chains with rhythmical soluble-insoluble changes. Journal of the American Chemical Society, 124, 8095-8098. http://dx.doi.org/ $10.1021 / \mathrm{ja} 012584 \mathrm{q}$

Yoshida, R., Takahashi, T., Yamaguchi, T., \& Ichijo, H. (1996). Self-oscillating gel. Journal of the American Chemical Society, 118(21), 5134-5135. http://dx.doi.org/ 10.1021/ja9602511

Yoshida, R., Uchida, K., Kaneko, Y., Sakai, K., Kikuchi, A., Sakurai, Y., \& Okano, T. (1995) .Comb-type grafted hydrogels with rapid deswelling response to temperature changes. Nature, 374, 240-242. http://dx.doi.org/ 10.1038/374240a0

Yoshihiro, I., Masayuki, N., \& Yoshida, R. (2003). Temperature control of the Belousov-Zhabotinsky reaction using a thermoresponsive polymer. Langmuir, 19, 9577-9579. http://dx.doi.org/ 10.1021/la0355242

\section{Copyrights}

Copyright for this article is retained by the author(s), with first publication rights granted to the journal.

This is an open-access article distributed under the terms and conditions of the Creative Commons Attribution license (http://creativecommons.org/licenses/by/3.0/). 